\title{
Difficult Decisions
}

\section{Medical or surgical treatment for Crohn's disease?}

\author{
R.N. Allan \\ The General Hospital, Steelhouse Lane, Birmingham B4 6NH, UK.
}

\section{Introduction}

A physician commenting on the indications for surgery in Crohn's disease must first establish his credentials. An appointment in a combined medical and surgical gastroenterology unit where more than 1500 patients with inflammatory bowel disease have been treated in close collaboration with surgeons having unrivalled experience in the surgical treatment of Crohn's disease may perhaps suffice.

Since Crohn's disease is not a single disease entity but a wide variety of disorders masquerading under a single name a careful evaluation of each symptomatic patient must precede a decision to advise medical or surgical treatment.

\section{Evaluating the symptomatic patient and appropriate management}

Treatment is determined by the nature, frequency and severity of symptoms including the impact on the patient's ability to work or care for their family. The symptomatic patient requires careful evaluation to determine the cause of their symptoms. The radiologist can assess the site and extent of macroscopic disease, the histopathologist is needed to review the histology of biopsy material and the microbiologist to exclude specific infection while the haematologist and clinical biochemist help to evaluate disease activity.

Appropriate medical or surgical treatment can only be considered once the nature, severity and duration of symptoms has been assessed and the site and extent of macroscopic disease defined. Physicians considering surgical treatment for patients with Crohn's disease must first evaluate the benefits and limitations of specific medical treatment.

Correspondence: R.N. Allan M.D., Ph.D., F.R.C.P.

Received: 8 June 1988

\section{What can medical treatment achieve?}

Short-term treatment to control diarrhoea with codeine phosphate, diphenoxylate or loperamide may be all that is required while diarrhoea resulting from impaired bile salt absorption in patients with extensive distal ileal disease or after ileal resection can be effectively treated with bile salt binding agents such as cholestyramine.

Sulphasalazine is significantly superior to placebo in the short-term treatment of ileo-colonic and colonic Crohn's disease while its disadvantages including headache, nausea and skin rashes can be overcome using new derivatives such as 5-aminosalicylate. ${ }^{1-3}$ Corticosteroid therapy improves symptoms resulting from inflammatory disease initially but the benefit is not sustained. ${ }^{1} \mathrm{~A}$ few patients may benefit from longer term corticosteroid therapy. ${ }^{4}$ Side effects are common, particularly moon face, fluid retention, disturbance of sleep pattern and mood change. The role of immunosuppressive agents is not clearly established. The American controlled trials found it no better than placebo treatment while other studies suggest that it has a role particularly to reduce the required dose of corticosteroids. ${ }^{1,3,5,6}$ Severe side effects are uncommon but include leukopenia and acute pancreatitis. No controlled study has demonstrated any prolonged benefit. Metronidazole has an efficacy equivalent to sulphasalazine and is particularly valuable in treating patients with perianal disease. Once again controlled studies have only demonstrated short-term benefit. ${ }^{7}$

Dietary manipulation is an attractive form of therapy since it has potential benefit without adverse effects. Preliminary work suggested that a high carbohydrate fibre-rich diet and low in sugar could reduce the relapse rate in Crohn's disease but a national controlled trial of patients with quiescent or mildly active Crohn's disease found no significant benefit from these dietary changes. ${ }^{8-10}$ 
A small controlled trial has shown that exclusion diets are helpful in relieving symptomatic patients with active Crohn's disease but unfortunately there were marked differences between the patient groups which made interpretation of the results difficult. ${ }^{11}$ Equivalent short-term results can be obtained using either elemental diets or oral prednisolone, although in practice oral prednisolone and a normal diet is a more realistic regimen for the patient. Enteral feeding can induce remission in active Crohn's disease but practical difficulties limit its use. ${ }^{12,13}$

Controlled studies have shown that the addition of parenteral nutrition to conventional management of acute colitis does not improve the outcome. Parenteral nutrition plays an important supportive role in severely malnourished patients and those with post-operative complications but there is no evidence that it has a primary therapeutic role. ${ }^{14-16}$

\section{Summary of medical treatment}

The short-term benefits of specific medical treatment in patients with symptomatic Crohn's disease are well established. However, there is no evidence that specific medical treatment, modification of diet, enteral or parenteral feeding alter the medium or long-term outcome. Thus surgical treatment remains an important part of overall management.

\section{Management at specific sites and indications for operation}

Oesophageal involvement is rare. Symptoms, usually of painful dysphagia, are readily relieved with oral corticosteroid therapy. Surgery is rarely, if ever, needed. ${ }^{17}$ Symptomatic gastro-duodenal disease results from strictures of the second or third part of the duodenum. Surgical treatment (by'-pass with gastrojejunostomy) is reserved for persistent or recurrent obstructive symptoms. ${ }^{18}$

Diffuse small bowel Crohn's disease is uncommon but poses major challenges in management. Symptoms include persistent general malaise, anorexia, weight loss, together with growth retardation in children. Oral corticosteroid therapy is usually needed but regular re-evaluation is important since, with time, many patients develop short fibrous strictures which cause recurrent episodes of subacute obstruction which can be effectively resolved by strictureplasty or local resection. Laparotomy in these patients is sometimes valuable to ensure that a mechanical cause for symptoms has not been overlooked.

\section{Ileal disease}

Most patients with ileocaecal disease have already developed ileal strictures at first presentation. Symptoms consist of intermittent shortlived obstructive episodes which, if more persistent, resolve rapidly with intravenous fluid therapy and nothing by mouth. Patients are usually asymptomatic between episodes and specific drug treatment is not required. Recurrent or severe episodes are readily relieved by distal ileal resection or strictureplasty. Careful examination of the small gut at laparotomy is important to avoid overlooking other short strictures. ${ }^{19,20}$ Local abscess complicating distal ileal disease is an indication for surgical treatment. A mass is often palpable in the right lower quadrant, associated with symptoms of fever, general malaise and weight loss. Psoas abscess presents with a flexion deformity of the right leg. Crohn's disease of the distal ileum may be found unexpectedly at laparotomy in patients presenting with symptoms suggestive of acute appendicitis. The appendix should be removed for histological examination. The ileum is only resected if fibrous strictures are present. ${ }^{21}$

Macroscopic disease associated with persistent enterocutaneous fistula is an indication for surgical treatment. Spontaneous enterocutaneous fistulae are uncommon but do occur as a presenting feature of recurrent disease. Post-operative enterocutaneous fistulae with no macroscopic Crohn's disease will heal with supportive therapy alone provided that there is no distal obstruction. Enterocutaneous fistula following laparotomy for suspected appendicitis arises from adjacent distal ileum damaged at surgery and not from the appendix stump itself. ${ }^{22}$ Entero-enteric fistula is not in itself an indication for surgery but surgical treatment is often required for the associated stenotic disease. ${ }^{23}$ Surgical treatment is usually needed for entero-vesical fistula and involves resection of the macroscopic Crohn's disease and oversewing of the bladder at the site of fistula formation. ${ }^{24}$

Most patients with non-obstructing ileal disease are asymptomatic and thus do not need specific medical treatment. In those patients with general malaise, fever, anorexia and weight loss (provided there is no evidence of local abscess formation) short-term remission can be induced with either oral sulphasalazine or prednisolone by mouth in the more severely ill. Many patients eventually develop local stricture formation with intermittent obstructive episodes. Severe or recurrent symptoms are an indication for local resection. Growth retardation is an indication for surgery in non-obstructing ileal disease. ${ }^{25,26}$

Laparotomy is sometimes worthwhile in sympto- 
matic patients since unexpected mechanical obstructive features such as a small bowel loop caught up by adhesions may be found which is easily overlooked using standard radiological techniques. Patients have suffered in the past from extensive ileal resections. This should no longer be a problem since resection should be confined to the most severely affected area and undertaken only in those patients with persistent or recurrent symptoms. Less severely affected residual disease can be left in situ.

\section{Ileo-colonic disease}

Patients with ileo-colonic disease and involvement of the adjacent caecum and ascending colon are managed in a similar way to those patients with ileocaecal disease alone. ${ }^{27}$ Symptoms in this group are usually caused by stricture formation in the distal ileum.

\section{Extensive colonic disease}

Remission can be induced in most patients with severe acute colitis using intensive medical treatment (intravenous fluids, electrolyte replacement, intravenous corticosteroid therapy, nil by mouth and blood transfusion when necessary). Emergency colectomy is required in a few patients who do not improve within a few days using this intensive regime. After initial improvement with medical treatment most patients with colonic disease experience persistent diarrhoea, abdominal discomfort, weight loss, lethargy and general malaise. Only a few patients (about 10\%) have prolonged remission either spontaneously or after specific medical treatment. A few patients probably benefit from the prolonged use of low dose oral prednisolone.

Surgical treatment is therefore often required because so few patients with colonic disease have a prolonged remission. Most are chronically ill with symptoms only somewhat ameliorated by medical treatment. ${ }^{28,29}$ The surgical options include ileostomy alone, colectomy and ileorectal anastomosis or panproctocolectomy. ${ }^{27}$ Ileostomy alone usually only relieves the symptoms for a few months.

The prospect of major surgery which often includes a permanent stoma naturally deters both the patient and their doctors from accepting surgical treatment. Patients commonly defer surgical treatment although post-operatively they often wish they had undergone surgical treatment earlier because of the dramatic relief of symptoms and their restoration to good health. The mean interval from diagnosis to colectomy and ileorectal anastomosis or panproctocolectomy in our own series is 4 and 6 years respectively. ${ }^{30-32}$
Surgical treatment in extensive Crohn's colitis is sometimes required for either massive haemorrhage or cancer of the colon complicating longstanding Crohn's colitis.

\section{Distal colonic Crohn's disease}

This is a common site in the elderly patient and often associated with diverticular disease. The disorder usually runs a benign course but urgent surgery may be required occasionally for colonic perforation occurring either at presentation or unexpectedly during follow-up. ${ }^{33,34}$ Perianal disease often looks unsightly but usually causes little in the way of symptoms. Metronidazole is effective for the treatment of secondary infection, but perianal abscess requires surgical drainage. Severe perianal disease is occasionally the primary indication for extensive colonic resection. ${ }^{35}$

\section{Timing of surgical intervention}

There is a tendency among patients and physicians to delay surgical treatment in the hope that either time or medical treatment will bring sustained benefit or because of anxiety about the risk of postoperative complications and recurrent disease.

Controlled studies have shown no benefit with prolonged medical treatment so patients should not be exposed to the hazards of such therapy with no prospect of benefit. Delaying inevitable surgical treatment will not reduce the incidence of postoperative complications which can anyway be minimized in experienced hands.

\section{Recurrent disease}

Surgical treatment is often delayed because of the possibility of developing recurrent disease. The impact of recurrent disease on the individual is much less than that of the initial disease and the problems have often been exaggerated. Recurrent disease is infrequent and nearly always confined to short segments of the gut at or around the site of the previous anastomosis. They induce intermittent obstructive symptoms which are readily recognized and if they persist or recur are readily amenable to a further local resection with minimum morbidity and the patient once again is rapidly restored to good health. This is particularly true of fibrous stricture formation at or around the site of a previous ileal or ileo-colonic resection.

Recurrent disease is not always easy to manage. Occasionally extensive non-obstructive ileal disease complicates a short ileal resection and diffuse small bowel disease may occur after colectomy. These are exceptions to the normal outcome where recurrent 
disease is readily amenable to further local resection.

\section{Conclusions}

Appropriate specific medical treatment is a valuable short-term option in the management of Crohn's disease but surgical treatment is often the only

\section{References}

1. Summers, R.W.. Switz, D.M., Sessions, J.T. Jr. et al. National Co-operative Crohn's Disease Study: Results of drug treatment. Gastroenterology 1979, 77: 847.

2. Anonymous. The drug treatment of Crohn's disease. Drug Ther Bull 1986, 24: 13.

3. Saverymuttu, S.H., Gupta, S., Keshavarzian, A., Donovan, B. \& Hodgson, H.J. Effect of slow-release 5 -aminosalicylic acid preparation on disease activity in Crohn's disease. Digestion 1986, 33: 89-91.

4. Malchow, H., Ewe, K., Brandes, J.W. et al. European Co-operative Crohn's Disease Study: Results of drug treatment. Gastroenterology 1984, 86: 249.

5. O'Donoghue, D.P., Dawson, A.M., Powell-Tuck, J. et al. Double blind withdrawal trial of azathioprine as maintenance treatment for Crohn's Disease. Lancet 1978, ii: 955 .

6. Nyman, M., Hansson, I. \& Eriksson, S. Long-term immunosuppressive treatment in Crohn's disease. Scand J Gastroenterol 1985, 20: 1197-1203.

7. Ursing, B., Alm, T., Barany, F., Bergelin, I. et al. A comparative study of metronidazole and sulphasalazine for active Crohn's disease. Gastroenterology 1983, 83: 550 .

8. Heaton, K.W., Thornton, J.R. \& Emmett, P.M. Treatment of Crohn's disease with an unrefined carbohydrate fibre rich diet. $\mathrm{Br} \operatorname{Med} J$ 1979, 2: 764 .

9. Ritchie, J.K., Wadsworth, J., Lennard-Jones, J.E. \& Rogers, E. Controlled multicentre therapeutic trial of an unrefined carbohydrate, fibre rich, diet in Crohn's disease. Gut 1986, 27: A1278.

10. Levi, A.J. Diet in the management of Crohn's disease. (Editorial). Gut 1985, 26: 985-988.

11. Alun-Jones, V., Workman, E., Freeman, A.H., Dickinson, R.J., Wilson, A.J. \& Hunter, J.O. Crohn's disease: maintenance of remission by diet. Lancet 1985, ii: 177.

12. O'Morain, C.D., Segal, A.W. \& Levi, A.J. Elemental diet as primary treatment of acute Crohn's disease. $\mathrm{Br}$ Med J 1984, 288: 1859.

13. O'Morain, C., Segal, A.W., Levi, A.J. Elemental diets in treatment of acute Crohn's disease. Br Med J 1980, 281: 1173.

14. Dickinson, R.J., Ashton, M.G. \& Axon, A.T.R. Controlled trial of intravenous hyperalimentation and total bowel rest as an adjunct to the routine therapy of acute colitis. Gastroenterology 1980, 79: 1199.

15. Harford, F.J. Jr. \& Fazio, V.W. Total parenteral nutrition as primary therapy for inflammatory disease of the bowel. Dis Colon Rectum 1978, 21: 555. effective way of restoring patients to good health. Surgical morbidity can be minimized in experienced hands and the incidence of recurrent disease (which is infrequent) should not be over-emphasized. Recurrent disease is readily recognized and is usually amenable to further local resection.

Until the aetiology of Crohn's disease is established, surgical treatment will continue to play a central role in management.

16. Rhodes, J. \& Rose, J. Does food affect acute inflammatory bowel disease? The role of parenteral nutrition, elemental and exclusion diets. Gut 1986, 27: 471-474.

17. Geboes, K., Janssens, J., Rutgeerts, P. \& Vantrappen, G. Crohn's disease of the oesophagus. J. Clin Gastroenterol 1986, 8: 31-37.

18. Shepherd, A.F.I., Allan, R.N., Dykes, P.W., Keighley, M.R.B. \& Alexander-Williams, J. The surgical treatment of gastroduodenal Crohn's disease. Ann $R$ Coll Surg Engl 1985, 67: 382-384.

19. Higgens, C.S. \& Allan, R.N. Crohn's disease of the distal ileum. Gut 1980: 21: 933.

20. Alexander-Williams, J. \& Haynes, I.G. Up-to-date management of small bowel Crohn's disease. $A d v$ Surg 1987, 20: 245-264.

21. Vanek, V.W., Spirtos, G., Awad, M., Badjatia, N. \& Bernat, D. Isolated Crohn's disease of the appendix. Two case reports and a review of the literature. Arch Surg 1988, 123: 85-87.

22. Hawker, P.C., Givel, J.-C., Keighley, M.R.B., Alexander-Williams, J. \& Allan, R.N. Manägement of enterocutaneous fistulae in Crohn's disease. Gut 1983, 24: 284-287.

23. Givel, J.-C., Hawker, P., Allan, R., Keighley, M.R.B. \& Alexander-Williams, J. Entero-enteric fistula complicating Crohn's disease. J Clin Gastroenterol 1983, 5: 321-323.

24. Greenstein, A.J., Sachar, D.B., Tzakis, A. et al. Course of enterovesical fistulas in Crohn's disease. $\mathrm{Am}$ J Surg 1984, 147: 788-792.

25. Alperstein, G., Daum, F., Fisher, S.E. et al. Linear growth following surgery in children and adolescents with Crohn's disease: Relationship to pubertal status. J Pediatr Surg 1985, 20: 129-133.

26. Ferguson, A. Crohn's disease in children and adolescents. J R Soc Med 1984, 77: 30-34.

27. Allan, R.N., Steinberg, D.M., Alexander-Williams, J. \& Cooke, W.T. Crohn's disease involving the colon: an audit of clinical management. Gastroenterology 1977, 73: 723.

28. Elliott, P.R., Ritchie, J.K. \& Lennard-Jones, J.E. Prognosis of colonic Crohn's disease. Br Med J 1985, 20: 178.

29. Goligher, J.C. The long-term results of excisional surgery for primary and recurrent Crohn's disease of the large intestine. Dis Colon Rectum 1985, 28: 51-55. 
30. Ambrose, N.S., Keighley, M.R.B., AlexanderWilliams, J. \& Allan, R.N. Clinical impact of colectomy and ileorectal anastomosis in the management of Crohn's disease. Gut 1984, 25: 223-227.

31. Scammell, B., Ambrose, N.S., Alexander-Williams, J., Allan, R.N. \& Keighley, M.R.B. Recurrent small bowel Crohn's disease is more frequent after subtotal colectomy and ileorectal anastomosis than panproctocolectomy. Dis Colon Rectum 1985, 28: 770-771.

32. Cooper, J.C., Jones, D. \& Williams, N.S. Outcome of colectomy and ileorectal anastomosis in Crohn's disease. Ann $R$ Coll Surg Engl 1986, 68: 279-282.
33. Fabricius, P.J., Gyde, S.N., Shouler, P., Keighley, M.R.B., Alexander-Williams, J. \& Allan, R.N. Crohn's disease in the elderly. Gut, 1985, 26: 461.

34. Rhodes, $\cdot$ J. \& Rose, J. Crohn's disease in the elderly (Editorial). Br Med J 1985, 291: 1149-1150.

35. Keighley, M.R.B. \& Allan, R.N. Current status and influence of operation on perianal Crohn's disease. Int J Colorectal Dis 1986, 1: 104-107. 